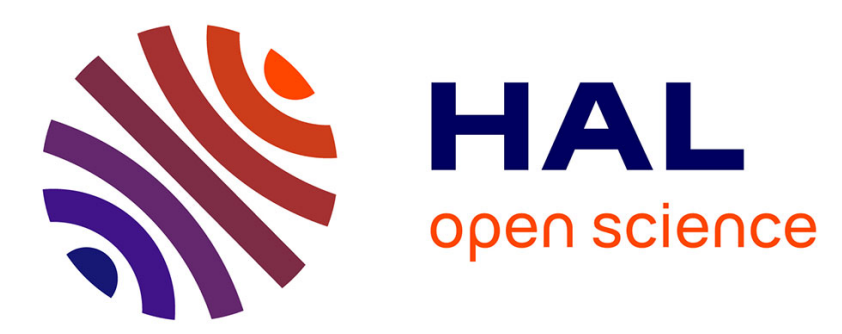

\title{
Pull-out behaviour of a glass multi-filaments yarn embedded in a cementitious matrix
}

Hana Aljewifi, Bruno. Fiorio, Jean-Louis. Gallias

\section{To cite this version:}

Hana Aljewifi, Bruno. Fiorio, Jean-Louis. Gallias. Pull-out behaviour of a glass multi-filaments yarn embedded in a cementitious matrix. EURO-C 2010 - Computational Modelling of Concrete Structures, Mar 2010, Schladming, Austria. hal-00563823

\section{HAL Id: hal-00563823 \\ https://hal.science/hal-00563823}

Submitted on 7 Feb 2011

HAL is a multi-disciplinary open access archive for the deposit and dissemination of scientific research documents, whether they are published or not. The documents may come from teaching and research institutions in France or abroad, or from public or private research centers.
L'archive ouverte pluridisciplinaire HAL, est destinée au dépôt et à la diffusion de documents scientifiques de niveau recherche, publiés ou non, émanant des établissements d'enseignement et de recherche français ou étrangers, des laboratoires publics ou privés. 


\title{
Pull-out behaviour of a glass multi-filaments yarn embedded in a cementitious matrix
}

\author{
H. Aljewifi, B. Fiorio and J.L. Gallias
}

Université de Cergy-Pontoise, Laboratoire de Mécanique et Matériaux du Génie Civil

5 Mail Gay-Lussac, Neuville sur Oise, 95031 Cergy-Pontoise cedex, France

hana.aljewifi@u-cergy.fr, bruno.fiorio@u-cergy.fr, jean-louis.gallias@u-cergy.fr

\begin{abstract}
This paper describes the pull-out behavior of glass multi-filaments yarns embedded in a cementitious matrix. The pull-out behavior is characterized by direct pull-out tests performed on different glass rovings. For these tests, different pre-treatments of the roving are used, that induce different impregnation patterns. In this way, the effect of the impregnation on the pull-out behavior is characterized. The effect of the constitutive parameters of the yarn on the mechanical behavior is also studied through the use of three different glass yarns for the experimental study.
\end{abstract}

\section{INTRODUCTION}

\subsection{Textile reinforced concrete}

Textile reinforced concrete (TRC) is a new cementitious composite that appeared in the early 1980's, when the combination of new yarn types with 3Dproduction processes leads to an increasing number of new textile applications. Materials used for TRC application are mainly alkali-resistant glass fibres and carbon fibres. The yarn structures include cabled yarns and friction spun yarns which were developed to improve the bonding behaviour. They both have a structure that looks like the one of steel reinforcements with rods.

The development of TRC is based on the fundamentals of shortcut glass fibre reinforced concrete. In order to increase the effectiveness of the fibres embedded in the concrete matrix, the fibres are aligned in the direction of the tensile stresses similar to ordinary steel reinforced concrete. Textile reinforced concrete offers many advantages compared to traditional concrete (Hanisch and al.,2006 ). The most important reason for a reinforcement of concrete parts with textiles is that the concrete parts can be very thin as there is no risk of corrosion of the reinforcement materials. This allows to reduce the weight of the concrete parts, and therefore to contribute to the reduction of the environmental impact of construction. In addition, the reinforcement is more flexible and therefore the shape of the concrete elements can be varied in a wide range.

\subsection{Multi-filaments reinforcement}

\subsubsection{Yarns characteristics}

Yarns are multi-filaments reinforcements made of a bundle of elementary fibres, so-called filaments. One yarn consists of several hundreds up to thousands of single filaments. Therefore the fineness of the yarn, in tex $(\mathrm{g} / \mathrm{km})$, depends on the number of filaments, filament diameter (range between 10 to $30 \mu \mathrm{m}$ ) and fibre density.

Filaments can be gathered in two different ways to produce a yarn: direct roving and assembled roving. Direct roving consists in a mass agglomeration of thousands of single filaments, coated with a sizing (see below). Assembled roving consists in the agglomeration of strands, themselves constituted from hundreds of single filaments. Assembled roving are a three levels structure (filament-strand-yarn), when direct roving presents a two level structure (filamentyarn).

In most of the applications, filaments are coated with a sizing which goal is to enhance the interaction with the matrix or to ease the building process of the yarn. The sizing material is a chemical mixture of polyhydroxyphenols, silane, polymer emulsion (PVAC) and additives. The detail of the chemical composition of the sizing is generally unknown, because of the industrial protection imposed by manufacturers.

The type of sizing influences the interfacial properties of the cement matrix - filaments bond. Therefore, the mechanical properties of TRC may be influenced by the sizing, as the quality of the adhesion 
between filaments and matrix influences the composite performances.

But the main element that influences the mechanical comportment of yarns reinforced concrete is the specific structure of the yarn itself. The tensile loadstrain relationship of the yarn is significantly influenced by the specific organisation of the filaments in the yarn (Chudoba et al. 2006). If all filaments in the yarn were strictly straight and aligned, the stress in each filament of a yarn submitted to a given strain should be homogeneous in the yarn and the stressstrain relationship of the yarn would correspond to those of filaments, i.e. to the linear elastic brittle behaviour of the bulk material, in the case of glass or carbon filaments. In this case, the failure of the yarn should be associated to the simultaneous failure of all constitutive filaments.

Real yarns lead to a different behaviour, as filaments are not initially aligned. As an example, Figure 1 shows the tensile behaviour of a glass yarn measured by the way of a direct tensile test. The first stage of the loading is characterized by the progressive stiffening of the mechanical behaviour, induced by the differed tension of the filaments due to their initial mis-alignement. When all filaments are tensed, the load-strain curve is linear until the first filaments begin to fail. This results in the progressive softening of the behaviour until the load reaches its maximum values $\mathrm{P}_{\max }$. For increasing strain, filaments breaking continue until full failure of all filaments. Residual friction between failed filaments then results in a residual load that progressively reduces to zero for high strain. The main observation is that during yarn elongation, the filaments work almost independently one from the other, and that the yarn behaviour results from the coupling action of the individual behaviour of all yarns.

\subsubsection{Influence of the yarn impregnation on the me- chanical behaviour}

Due to the specific geometry of the yarn and to the penetration of the cementitious matrix inside the yarn during the casting of TRC, the behaviour of impregnated yarn in the cementitious matrix is very dissimilar from the behavior of ordinary steel rods. The penetration of the cementitious matrix is not homogeneous: the cross section of the impregnated yarn shows that the outer filaments are embedded in a hardened cement paste that provides them a good anchorage (figure 2). The penetration depth of the cement paste inside the yarn is not sufficient to ensure a full impregnation of the yarn. The inner filaments are not reached by the hydrated cement paste and thus are not directly anchored in the cementitious matrix. Only the friction between these filaments can generate a certain bond resistance when the yarn is pulled out, when differential slips appear between filaments. This phenomenon induces a nonuniform stress and strain distribution in the yarn.

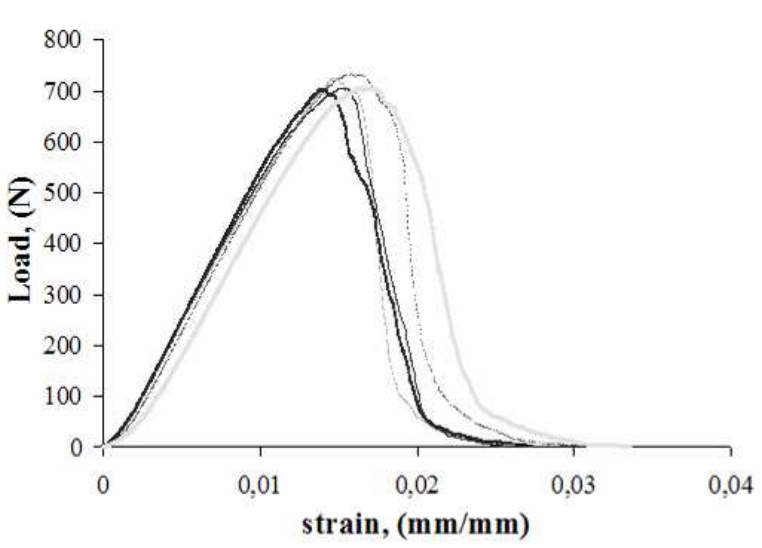

Figure 1. Typical load vs. strain curve observed for multifilaments yarn in direct tension.
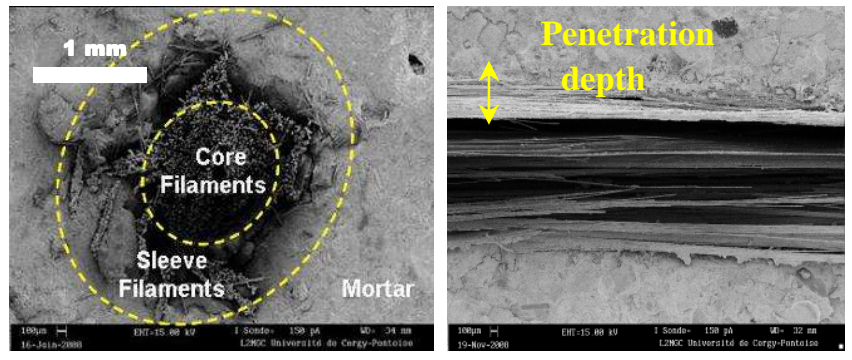

Figure 2. Cross section (left); longitudinal section (right) of multi-filaments yarn embedded in micro concrete.

Two interactions between the yarn and the matrix can been formed. Ohno et al., 1994 \& Langlois, 2004 assume two families of yarns: sleeve filaments with direct contacts with the matrix and core filaments without direct contacts. Sleeve filaments are mechanically anchored to the matrix. Core filaments are submitted to tension due to friction with sleeve filaments. As filaments are not straight and parallel into the yarn, a filament that is located in the center part of the yarn, in a given cross section of the yarn, can be located in the impregnated peripherical part of the yarn in another cross section. This means that the relative importance of the sleeve filaments and core filaments does not only depends on the impregnation process, but depends also on the embedded length of the yarn. The longer this length is, the more numerous the anchored sleeves filaments are.

This phenomenon also depends on the fiber / matrix chemical bond strength (Kabele et al., 2006) that conditions the filament debonding and the filament / filament and filament / matrix slip properties. From this point of view, the sizing may also play an important part in the pull-out behaviour.

As explained, the impregnation process greatly influences the bond conditions of each individual filament of the yarn. The resulting bond conditions of the yarn are then also mainly guided by the impregnation process, as well as by the matrix and yarn properties. This specificity of multi-filaments reinforcements, compared to monolithic reinforcements, induces a very specific mechanical behaviour, which 
cannot be modelized with the same methods as monolithic reinforcements. The aim of this paper is to give some experimental explaination of the mechanisms involved in the yarn / matrix interaction, and to provide the modelization community with experimental data that describe the pull-out behaviour of multi-filaments reinforcement.

\section{EXPERIMENTAL PROCESS}

\subsection{Objectives of the experimentation}

The hereafter-presented experimentation focuses on the influence of the fibre impregnation on the pullout behaviour of a glass multi-filaments yarn embedded in a cementitious matrix, in relation with the constitutive parameters of the yarn. In this experiment, pull-out tests have been performed to characterize the micromechanical behaviour of the multifilaments yarn / cementitious matrix interface.

In these tests, a yarn was embedded into a matrix with various condition of impregnation and loaded in tension until the filaments slip, or break.

Parameters of the study were the yarn properties, the embedded length and the matrix impregnation. Yarn properties were controlled through the use of three different types of yarns. The impregnation was varying trough the use of three preparation process applied to the yarn before the casting of the pull-out samples.

\subsection{Materials}

\subsubsection{Glass yarn}

Three types of glass yarns (named in the following $\mathrm{OC} 1$, OC2 and SG2) have been used in this study. OC1 and OC2 yarns are made from E-glass filaments and came from a first manufacturer. SG2 yarn is made from AR-glass and came from a second manufacturer. OC1 and SG2 yarns are assembled rovings. OC2 is a direct roving (see 1.2.1). The main characteristics of these yarns are given in table 1. Figure 3 gives the results of tensile tests performed on the three yarns. These tests were performed on $10 \mathrm{~cm}$ long yarns of the three studied type. The five curves in each chart correspond to the same type of yarn and give an idea of the variability classically observed in the case of yarns.

Table 1. Characterization of the glass multi-filaments yarns (n: number of strands in assembled rovings).

\begin{tabular}{|c|c|c|c|c|c|}
\hline Yarn & $\begin{array}{c}\begin{array}{c}\text { Filament } \\
\text { diameter }\end{array} \\
\mu \mathrm{m}\end{array}$ & $\mathrm{n}$ & $\begin{array}{c}\frac{\text { Fineness }}{\text { tex }} \\
(\mathrm{g} / \mathrm{km})\end{array}$ & $\begin{array}{l}\text { Young's } \\
\frac{\text { modulus }}{\mathrm{GPa}}\end{array}$ & $\begin{array}{c}\text { Glass bulk } \\
\frac{\text { density }}{\mathrm{kg} / \mathrm{m}^{3}}\end{array}$ \\
\hline $\mathrm{OC} 1$ & 12 & 39 & 2400 & 57.73 & 2530 \\
\hline OC2 & 17 & I & 2400 & 59.38 & 2530 \\
\hline SG2 & 14 & 30 & 2450 & 49.11 & 2680 \\
\hline
\end{tabular}

\subsubsection{Cementitious matrix}

Fine grain (1.25 mm maximum size) CEM I 52.5 mortar was used as cementitious matrix. Mixing proportion was as follow: $\mathrm{W} / \mathrm{C}=0.5, \mathrm{~S} / \mathrm{C}=1.4$ and $\mathrm{SP} / \mathrm{C}=0.0035$ (W, C, S and SP are respectively the mass of water, cement, sand and superplasticizer used for the composition). The compressive and flexural strength were measured according to NF 196-1. Mean values of these properties were $55 \mathrm{MPa}$ and 10.83 MPa respectively.

\subsection{Samples}

\subsubsection{Samples preparation}

Samples were $3.4 \mathrm{~cm}$ diameter cylinder made from the mortar described in the previous part. A straight yarn was positioned along the axis of the cylinder.
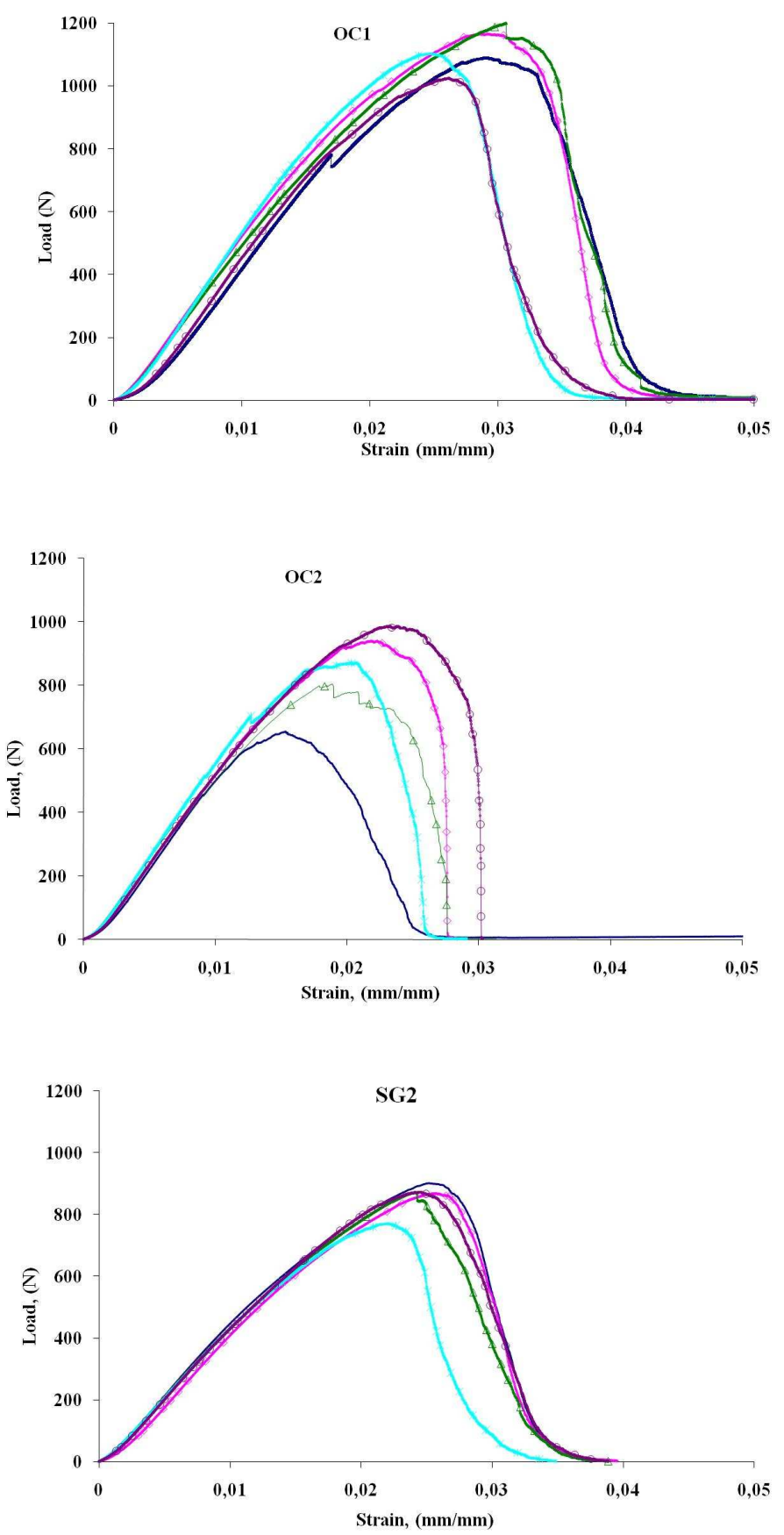

Figure 3. Tensile test on yarns. 
The height of the cylinder varied from 1 to $25 \mathrm{~cm}$, which results in a variation of the embedded length of the yarn.

One of the three hereafter described pre-treatment was applied to each yarn before casting the sample:

- Pre-wetting (W): yarn was saturated with water so that the inter-filaments voids are filled with water, which prevent the cement paste to enter the yarn during casting. It should be noticed that in this case, capillarity forces induce the agglomeration of the glass filaments which became more parallel than without this treatment.

- Drying (D): yarn was air dried at room temperature before casting. Capillarity leads to penetration of water and cement particles in the yarn at the time of casting. As the filaments act as a filter, penetration of cement particles into the yarn was limited.

- Cement pre-impregnation (PI): the yarn was manually saturated with a cement slurry before casting. Saturation was obtained by manual action on the yarn placed in a slurry batch. The cement slurry composition corresponds to the micro-concrete matrix cement paste composition.

After $24 \mathrm{~h}$ hardening at room conditions (about $50 \%$ relative humidity and $20^{\circ} \mathrm{C}$ ), samples were removed from mould and placed in $20^{\circ} \mathrm{C}$ water during 24 days. They were then removed from water for one day to allow the air drying of the yarn. The free end of the yarn was glued in between two epoxy plates for fastening in the pull-out device.

\subsubsection{Characterization of the yarn impregnation}

Aljewifi et al., 2010 have studied the impregnation of the yarns obtained from the three pre-treatments applied to the three types of yarns used in this study. Different methods of characterization were used, among them scanning electron microscopy (SEM) observation of longitudinal sections of yarns and flow tests.

The main result of these SEM observations is the strong influence of the pre-treatment on the impregnation. As an example, figure 4 gives the three SEM photographs corresponding to each pre-treatment applied to OC1 yarn. The pre-wetting of the yarn (W) leads to straight parallel mainly un-impregnated filaments. Conversely, the pre-impregnation with the cement slurry (PI) induces a full impregnation of the yarn, with filaments partially interlocked due to the mechanical action during pre-treatment. Dried yarn (D) shows an intermediate facies, with the main part of the filaments embedded in the matrix, which signifies that the free length of most of the filaments (the distance between two embedded points) is smaller than the length of the specimen $(4 \mathrm{~cm})$. Similar observations were made for all other types of yarns.

The penetration depths of the cementitious matrix in the yarns were estimated from the SEM observations. An impregnation index $i_{y}$ was calculated from
Table 2. Diameter of the impregnated yarns $(\mathrm{mm})$ and values of the impregnation index iy (\%).

\begin{tabular}{llll}
\hline & W & D & PI \\
\hline OC1 & $3.52 \mathrm{~mm}$ & $3.26 \mathrm{~mm}$ & $4.19 \mathrm{~mm}$ \\
& $38 \%$ & $67 \%$ & $100 \%$ \\
OC2 & $2.69 \mathrm{~mm}$ & $3.39 \mathrm{~mm}$ & $4.26 \mathrm{~mm}$ \\
& $24 \%$ & $19 \%$ & $100 \%$ \\
SG2 & $2.84 \mathrm{~mm}$ & $3.14 \mathrm{~mm}$ & $3.42 \mathrm{~mm}$ \\
& $29 \%$ & $70 \%$ & $100 \%$ \\
\hline
\end{tabular}

these values as the ratio of he impregnated area of the yarn to the apparent area of its cross section. Values of $i y$ for the different combinations of yarns and pre-treatments are given in table 2.

Flow tests realized by Aljewifi et al., 2009 give complementary information about the porosity of the impregnated yarn. This test allows to measure the water flow rate along an embedded yarn under a constant pressure gradient of $107.5 \mathrm{kPa} / \mathrm{cm}$.

For a given yarn, the measured flow rate decreases when the impregnation becomes more important (see figure 5). Figure 5 also shows that the lowest value of the flow rate corresponds to the PI pre-treated yarns and that this value is roughly independent from the type of yarn. This is the signature of a small water-flow inside the tortuous cement paste porosity of the impregnated yarn.
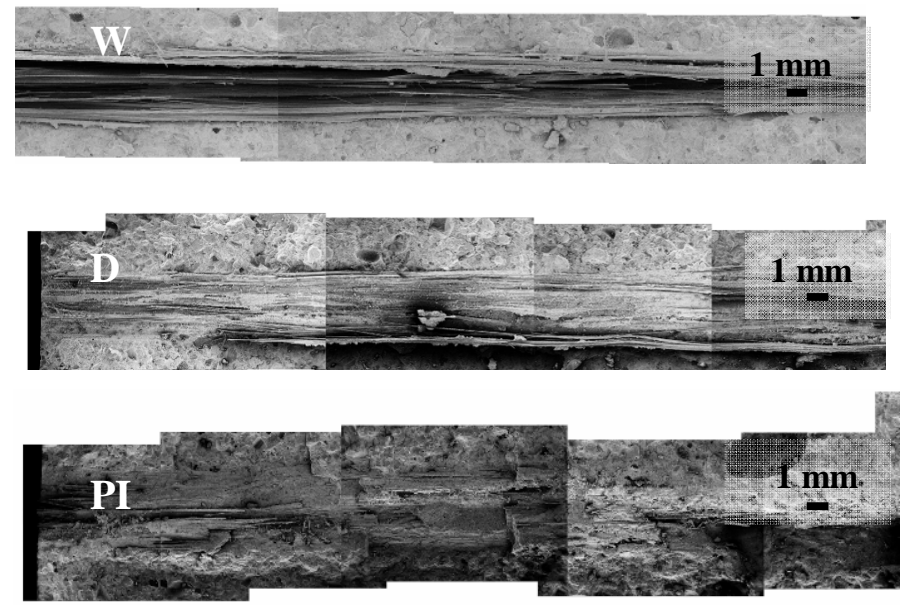

Figure 4. OC1 yarns; longitudinal sections corresponding to $\mathrm{W}$, $\mathrm{D}$ and PI yarn pre-treatment.

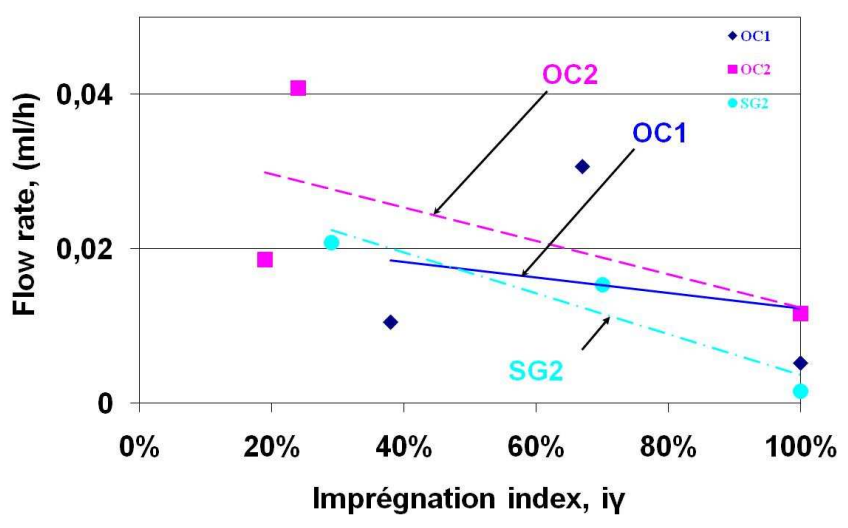

Figure 5. Flow rate vs. impregnation index iy. 

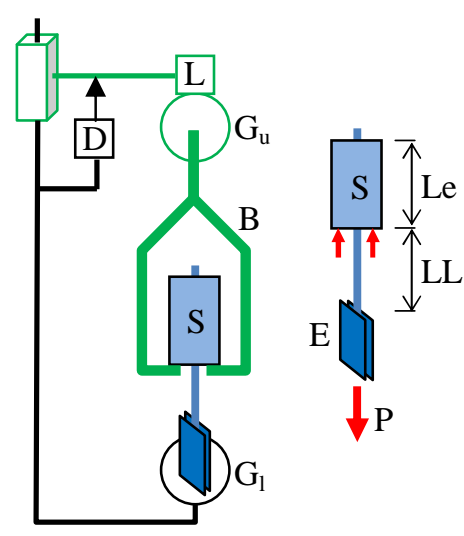

Figure 6. Experimental setup.

In the case of the lowest impregnation index, the flow rate is higher and influenced by the yarn type. This is explained by a flow of water that takes place inside the inter-filaments porosity of the unimpregnated center part of the yarn. As the water is in direct contact with the filaments in this case, the chemical composition of the filament surface (sizing) influences the flow, which explains the differences observed for the yarns in this situation.

As a conclusion of this part, it is shown that there are strong evidences that the yarn impregnation is only partial in most of the case. As a consequence, the pull-out behaviour of the yarn will be strongly influenced by this fact and the overall behaviour will diverge from the pull-out behaviour of monolithic reinforcements.

\subsection{Pull-out test}

Pull-out tests are performed on yarns embedded in a cylinder of micro-concrete. As explain in 2.3.1, the free end of the yarn (i.e. the end which is not embedded in the micro-concrete) is glued between two epoxy plates. A universal mechanical device is used to perform the tests (see also figure 6). The microconcrete cylinder is positioned in a specific basket clamped on the upper grip of the test device. The free end of the yarn is clamped on the lower grip of the tension device. The mortar cylinder is precisely centred so as to ensure that the tension load is applied parallel to the embedded yarn.

For all test, the free length LL of the yarn (i.e. the length of the yarn from the micro-concrete cylinder to the epoxy plates, figure 6) has a constant values of $10 \mathrm{~cm}$. Tests are realized at constant speed $\left(0.01 \mathrm{~mm} \cdot \mathrm{min}^{-1}\right)$.

In this test, a load $\mathrm{P}$ is applied to the tip of the yarn embedded in a cementitious matrix over an embedded length Le which was a parameter of the study.

In the case of monolithic fibre, a monotonic increase in the load $\mathrm{P}$ is accompanied by a displacement from the tip of the fibre and leads to progressive debonding along the fibre/matrix interface. Once the debonding process has reached the end of the embedded fibre length, a dynamic mechanism of pull-out is observed. Moreover, a displacement at the end of the free length is also accompanied by a displacement at the embedded end (Naaman et al., 1991).

In the case of yarn, the above described behaviour is observed for individual filaments but cannot be directly applied to the whole yarn.

\section{RESULTS}

\section{$3.1 \mathrm{Load} /$ displacement curves}

\subsubsection{Measurements}

As the stress is not homogeneous in all filaments of the tested yarns, it was chosen to present the results of the pull-out tests as load / displacement curves instead of stress / strain curves.

Load and displacement are measured through the press sensor. In particular, the displacement is

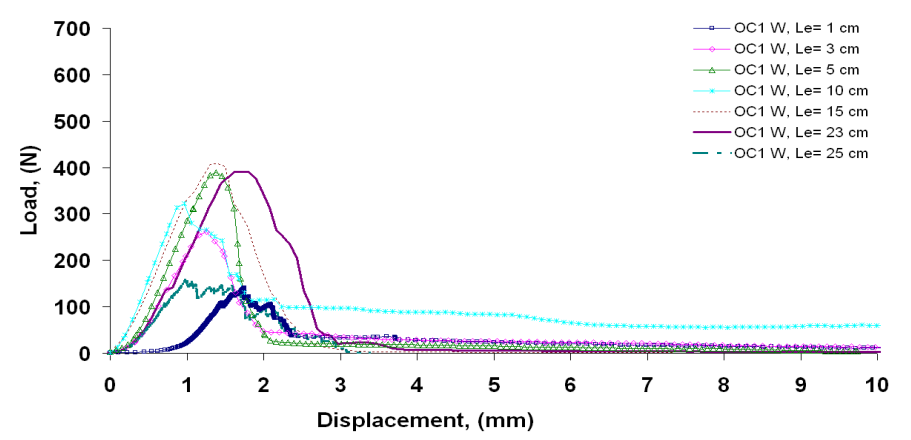

W pre-treated OC1 yarn

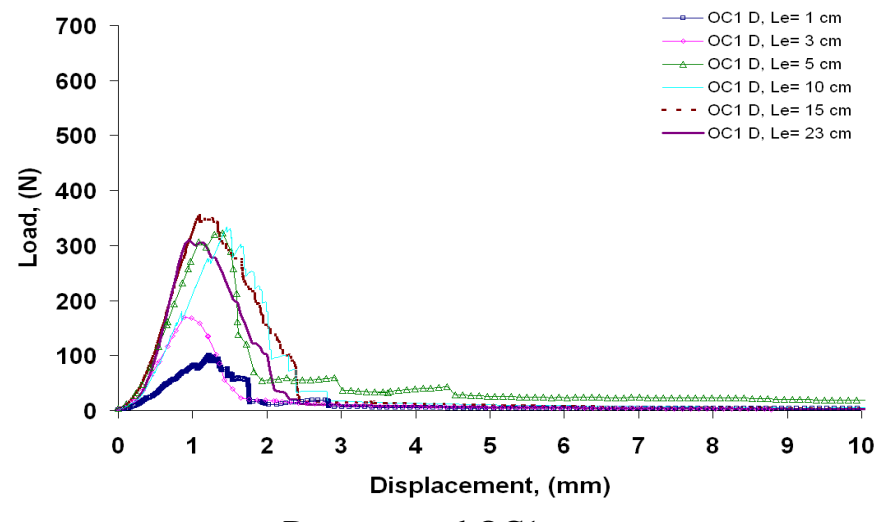

D pre-treated OC1 yarn

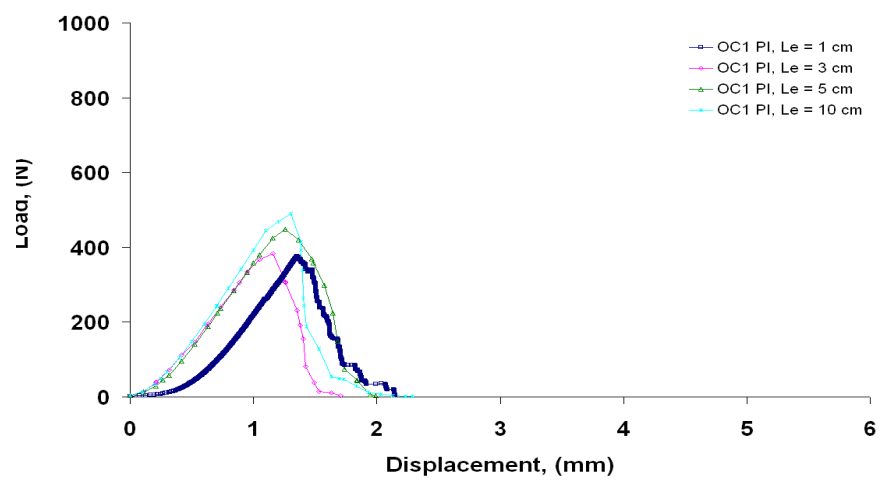

PI pre-treated OC1 yarn

Figure 7. Load vs. displacement curves for OC1 yarn and different embedded lengths in fine concrete. 
measured through the displacement transducer of the test device: it is the relative displacement of the upper grip supporting beam regardless to the lower grip support (figure 6). Therefore, the measured displacement is not directly the extracted length of the yarn but also take into account the strain of the free length of the yarn. As this length stay constant over all the tests, it is considered that the comparison between the behaviours observed in all different cases that have been tested remains pertinent. This assumption is clearly true when working with a given type of yarn. It remains roughly true for comparison between two different types of yarns, as yarns mechanical properties are in the same range.

Figures 7 to 9 give the load / displacement curves for each of the three tested yarns. Each figures presents three charts, one for each type of yarn's pretreatment. In each chart, the results corresponding to

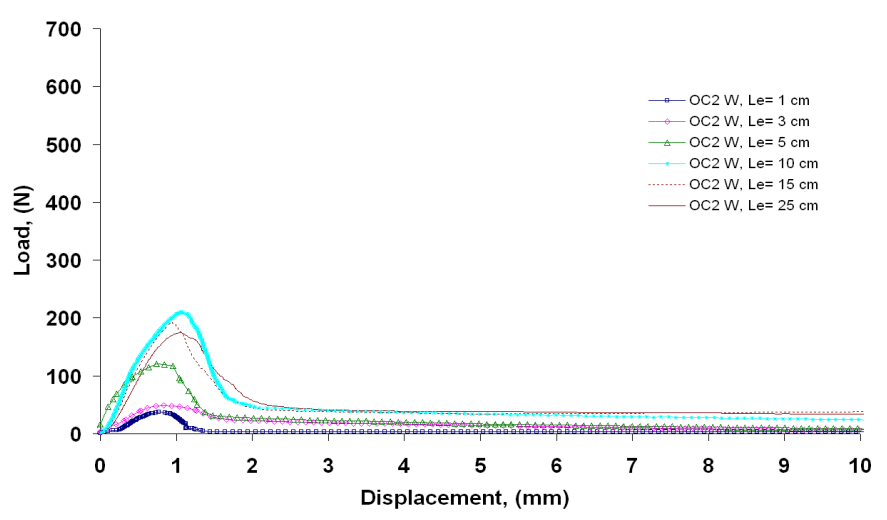

W pre-treated OC2 yarn

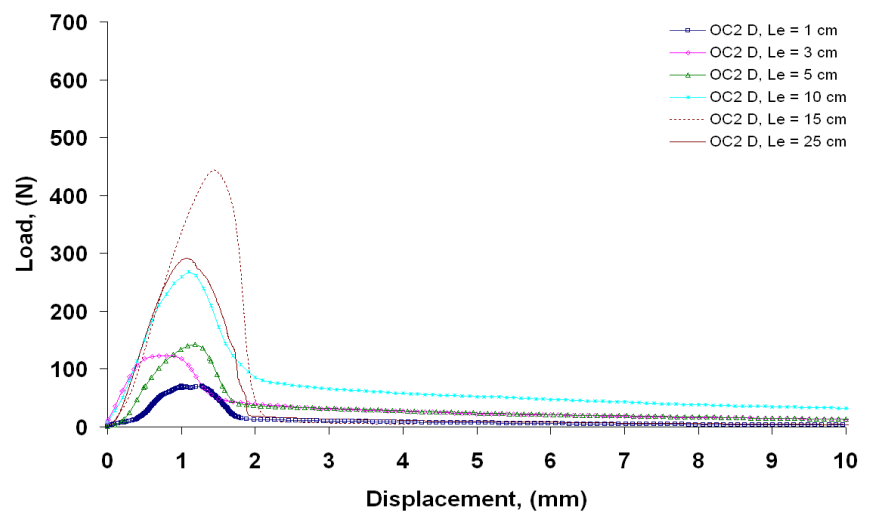

D pre-treated OC2 yarn

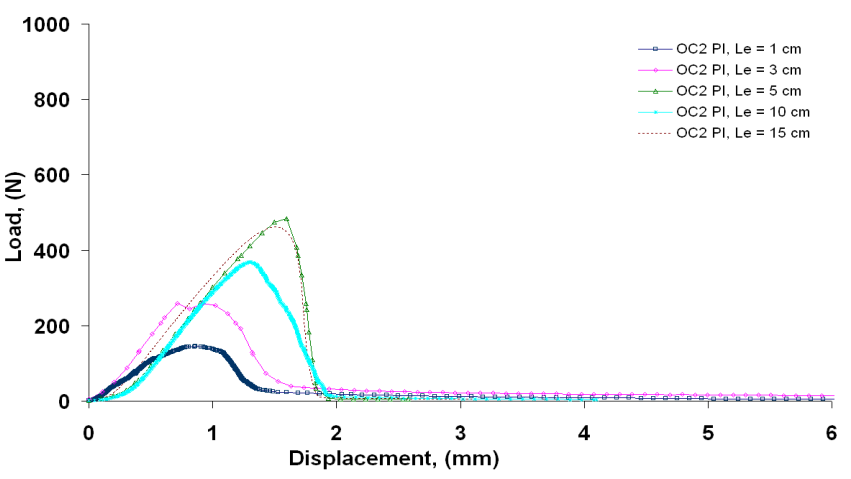

PI pre-treated OC2 yarn

Figure 8. Load vs. displacement curves for OC2 yarn and different embedded lengths in fine concrete. the different measurements made for a given embedded length are presented as a single average behaviour curve. This curve is obtained from three tests performed in the same conditions.

\subsubsection{Three stages behaviour}

Generally, pull-out curves are divided into three stages (Hegger and al., 2004). In our study, all of the obtained results obey this statement, except may be for the third stage, as explain later.

The first stage is determined by the elasticity of the adhesion bond and corresponds to the progressive tension of the filaments that constitute the yarn. Stiffening is generally observed at the beginning of the loading, associated to the delayed tension of the filaments. The slope of the linear ascending portion is not similar for all curves and seems to be an increasing function of the embedded length.

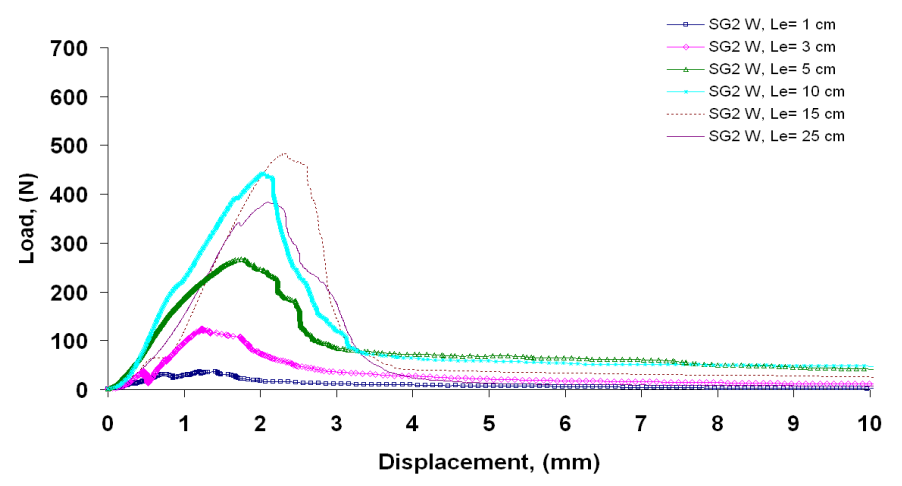

W pre-treated SG2 yarn

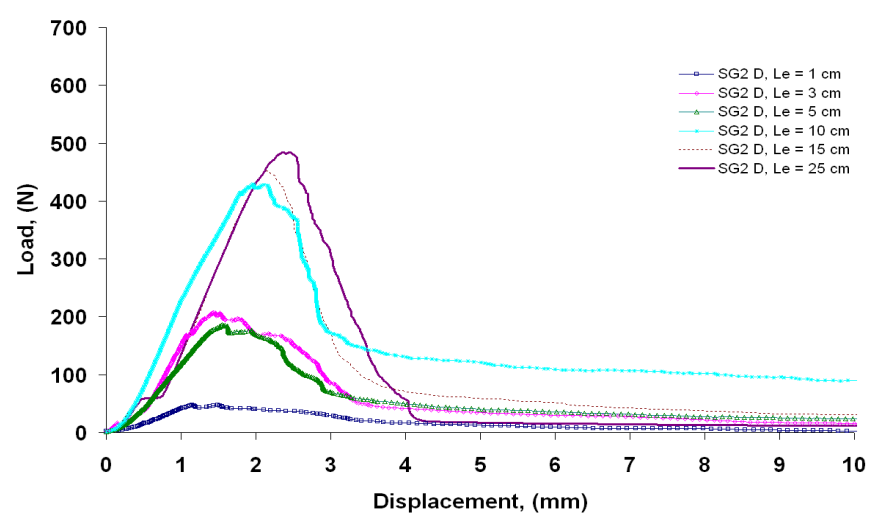

D pre-treated SG2 yarn

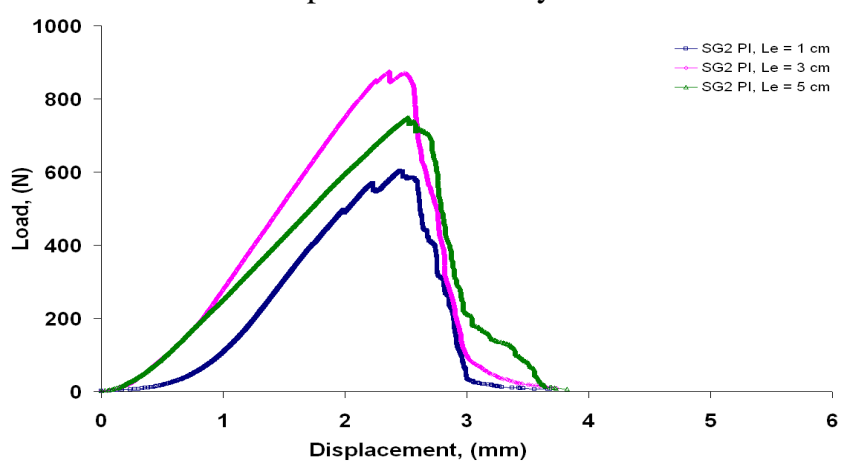

PI pre-treated SG2 yarn

Figure 9. Load vs. displacement curves for SG2 yarn and different embedded lengths in fine concrete. 
In the second stage of the behaviour, the chemical bond between the strands and the matrix break (the smooth surface of the filaments do not ensure a good mechanical anchorage of the strands on short length. The breaking of the strand / matrix bond is accompanied by filaments breaking. This phenomenon induces a smoothing of the mechanical behaviour. When broken filaments are in sufficient number, failure progressively appears as a slow decrease of the load.

After the breaking of all the filaments and strands (tensile or adhesion failure), broken filaments are extracted from the matrix. During this stage, frictional stresses appear at the filament / filament and filament / matrix contacts. This results in a residual load which progressively reduces to almost zero, when all filaments become extracted from the matrix. This observation corresponds to the third stage of the behaviour mentioned by Hegger and al., 2004.

\subsubsection{Complementary elements on the residual load} The values of the residual frictional load for all types of yarn and embedded lengths show a tendency of the residual load level to increase with the embedded length, which is consistent with the increase of contact points along the filaments. In some case,
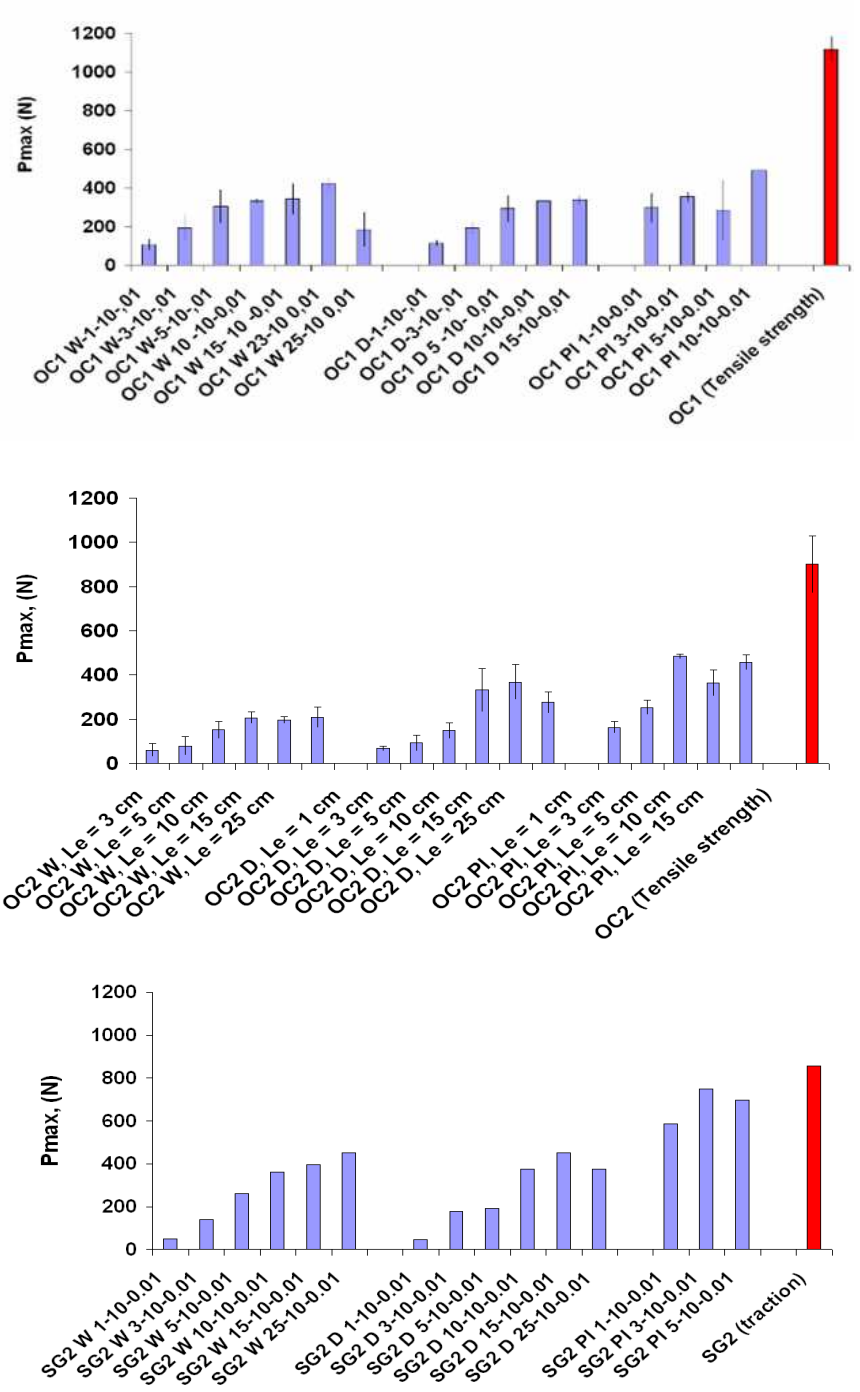

Figure 11. Values of $\mathrm{P}_{\max }$ vs. embedded length.
Before Pull-out test :
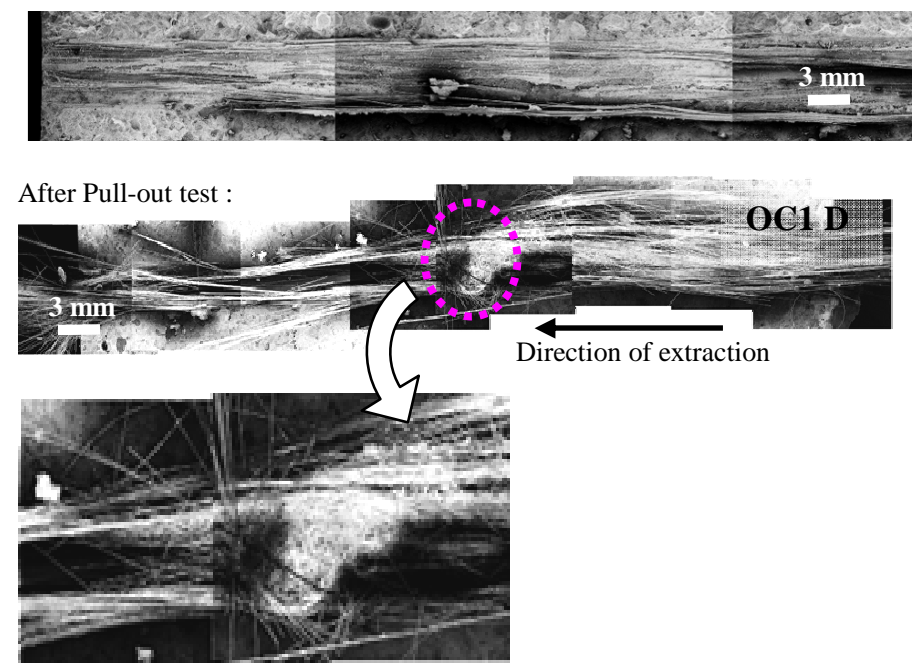

Figure 10. Longitudinal section of OC1 D yarn after pull-out test. Arrow: direction of extraction.

this tendency is not respected and some lower embedded length gives highest frictional level. This can be attributed to the appearance of local disorganization in the yarn, due to differential slip of the filaments. Evidences of this phenomenon have been seen on longitudinal sections of samples made after the pull-out test (figure 10). By comparison with reference longitudinal sections made before pull-out test, the structure of the loaded yarns has been disorganized. In some location, node looking structures (see detail on figure 10) appear and seem to be the consequence of the blocking of a group of filaments in a small cement cluster pulled by another groups of filaments.

It should be noted that this third stage of the behaviour is in some cases reduced to almost nothing. This is systematically the case for PI pre-treated yarns, whatever the embedded length was. The explanation is, that in this case, the anchorage length necessary to anchor the whole yarn (i.e. all its filaments) is very short. Most of the filaments' failures then take place in the vicinity of the surface of the concrete, producing failed filaments with short embedded length. As the embedded length of the failed filaments is short, the remaining frictional load is very low and comes back to zero for small extraction displacement.

\subsection{Behaviour law parameters}

\subsubsection{Maximum pull-out load $P_{\max }$}

Raw data described in 3.1 were used to determine the maximum value Pmax of the pull-out load during the test.

Values of Pmax are given in figure 11. As a general trend, it is seen that Pmax is an increasing function of the embedded length for the low values of the embedded length. For higher values of the embedded length, $\mathrm{P}_{\max }$ remains roughly constant but do not reach the tensile strength of the yarn, which indicates 
that a portion of the filaments remains inactive during the pull-out test. SG2 yarn gives the best efficiency (about $90 \%$ of the tensile strength), when $\mathrm{OC} 1$ and $\mathrm{OC} 2$ give lower efficiencies.

Concerning the effect of the pre-treatment, D and PI pre-treatment does not show major differences for the evolution of $\mathrm{P}_{\max }$ : PI pre-treatment gives higher values of $\mathrm{P}_{\max }$ than $\mathrm{D}$ pre-treatment, which itself gives higher values than $\mathrm{W}$ pre-treatment. In the case of $\mathrm{OC} 1$ yarn, values of $\mathrm{P}_{\max }$ are rather independent of the pre-treatment.

\subsubsection{Optimum embedded length and efficiency of} the yarn.

The minimum embedded length $\mathrm{L}_{\text {min }}$ necessary to reach the maximum value of $\mathrm{P}_{\max }$ was determined for each pre-treated yarn. The maximum value $\mathrm{P}_{\max \lim }$ of $\mathrm{P}_{\max }$ was determined as the average values of $\mathrm{P}_{\max }$ for
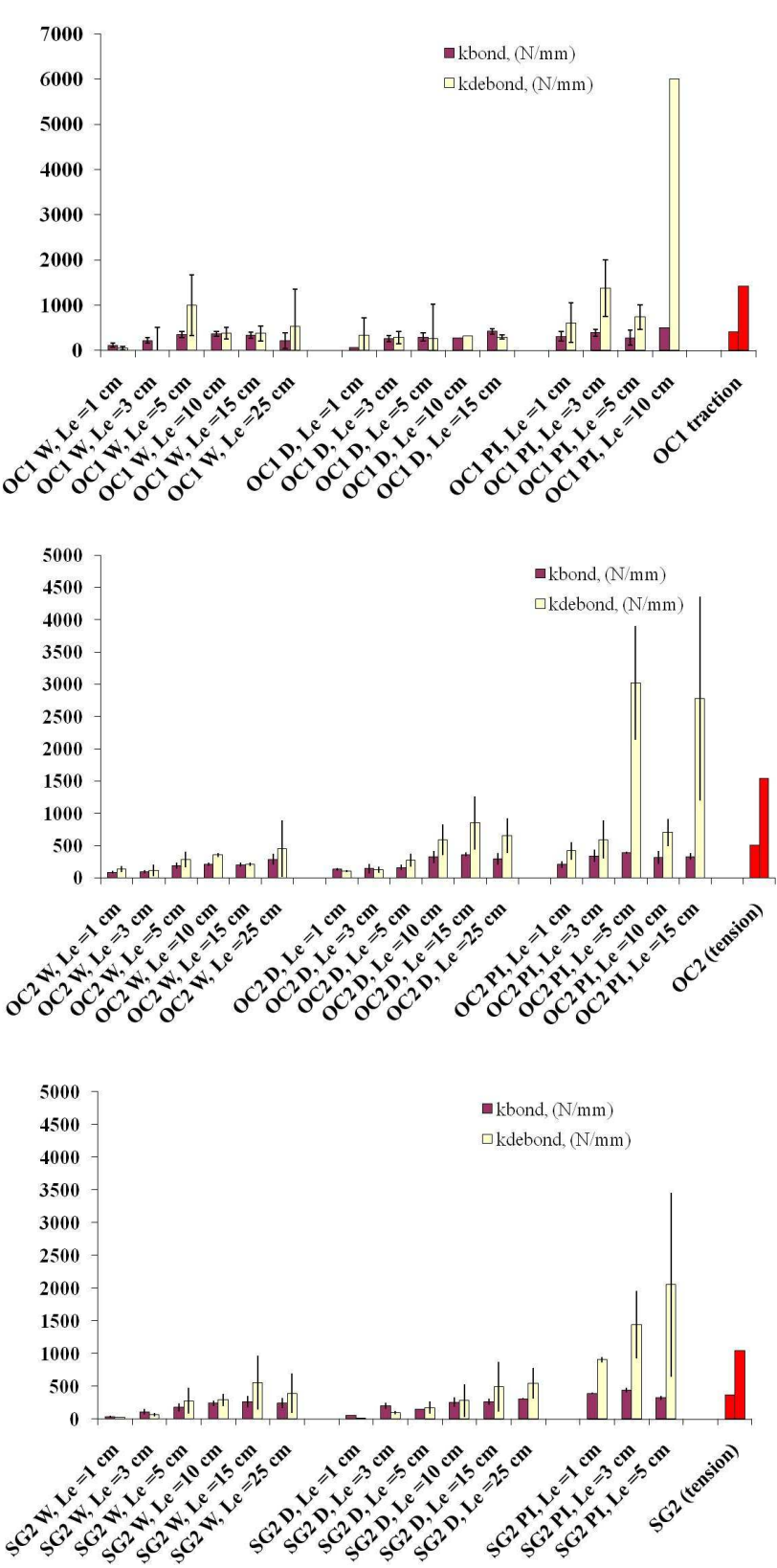

Figure 12. Values of $\kappa_{\text {bond }}$ and $\kappa_{\text {debond }}$ vs. the embedded length.
Table 3. Optimum embedded length and efficiency of yarns

\begin{tabular}{|c|c|c|c|c|}
\hline & & $\mathrm{L}_{\min }$ & $\mathrm{P}_{\max \lim }$ & $e_{p o}$ \\
\hline & & $\mathrm{cm}$ & $\mathrm{N}$ & $\%$ \\
\hline \multirow[t]{3}{*}{$\mathrm{OC} 1$} & W & 10 & 333 & 29 \\
\hline & $\mathrm{D}$ & 5 & 334 & 30 \\
\hline & PI & 3 & 354 & 34 \\
\hline \multirow[t]{3}{*}{ OC2 } & $\mathrm{W}$ & 10 & 206 & 21 \\
\hline & $\mathrm{D}$ & 10 & 367 & 36 \\
\hline & PI & 5 & 484 & 48 \\
\hline \multirow[t]{3}{*}{$\mathrm{SG} 2$} & W & 15 & 395 & 49 \\
\hline & $\mathrm{D}$ & 15 & 452 & 55 \\
\hline & $\mathrm{PI}$ & 3 & 748 & 81 \\
\hline
\end{tabular}

embedded length greater than $\mathrm{L}_{\text {min }}$. The pull-out efficiency $\mathrm{e}_{\mathrm{po}}$ was calculated as the ratio of $\mathrm{P}_{\max \lim }$ to the tensile strength of the yarn. Values of theses parameters are given in table 3 . The efficiency is all the more high that the pre-treatment favours the penetration of cement paste in the yarn. The best efficiency is obtained for SG2 yarn.

\subsubsection{Stiffnesses}

$\kappa_{\text {bond }}$ and $\kappa_{\text {debond }}$ are respectively the ascending and descending stiffnesses measured for the ascending and descending part of the behaviour curve. Calculation is made for load values in the range 0.5 to $0.8 \mathrm{P}_{\max }$. Figure 12 gives the values of these two parameters for the different configurations used in the study.

Values lower than those measured in direct tension (right bars on figure 12) reveal a lake of adhesion of the sleeve filaments. This is specially the case for OC2 W pre-treated yarn. OC2 and SG1 yarns give $\kappa_{\text {bond }}$ values for pull-out tests comparable to those measured in direct tension. $\kappa_{\text {debond }}$ is an increasing function of the embedded length. The observed values for $\kappa_{\text {debond }}$ are dependent of the pretreatment. In particular, PI pre-treated yarns give high values of $\kappa_{\text {debond}}$, allowing $\kappa_{\text {debond }}$ to reach the values measured in direct tension.

This signifies that in this case the anchorage of the sleeve filaments is very efficient and that this family of filaments behaves as if they were in direct tension.

\subsection{Core and sleeve filaments}

To evaluate the ratio between sleeve and core filaments, the ratio of the linear mass $m_{L e}$ of the extracted part of the yarn (damaged due to filaments failure) to the linear mass $m_{L L}$ of the undamaged yarn was determined after each pull-out test (figure 13). This ratio gives an idea of the amount of unanchored core filaments in the loaded yarn. As these filaments could include some small cement particles in between them, the value of the ratio is in some case an over estimated value of the real fraction of core filaments (this fact is particularly true for PI 


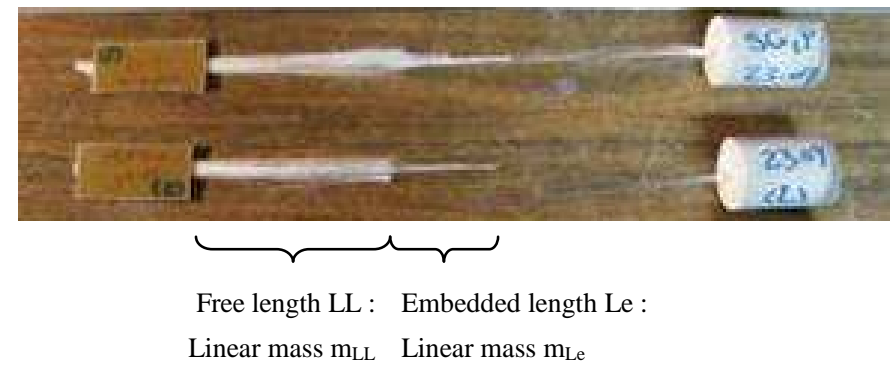

Figure 13. Determination of the yarn's linear masses after the pull-out test.
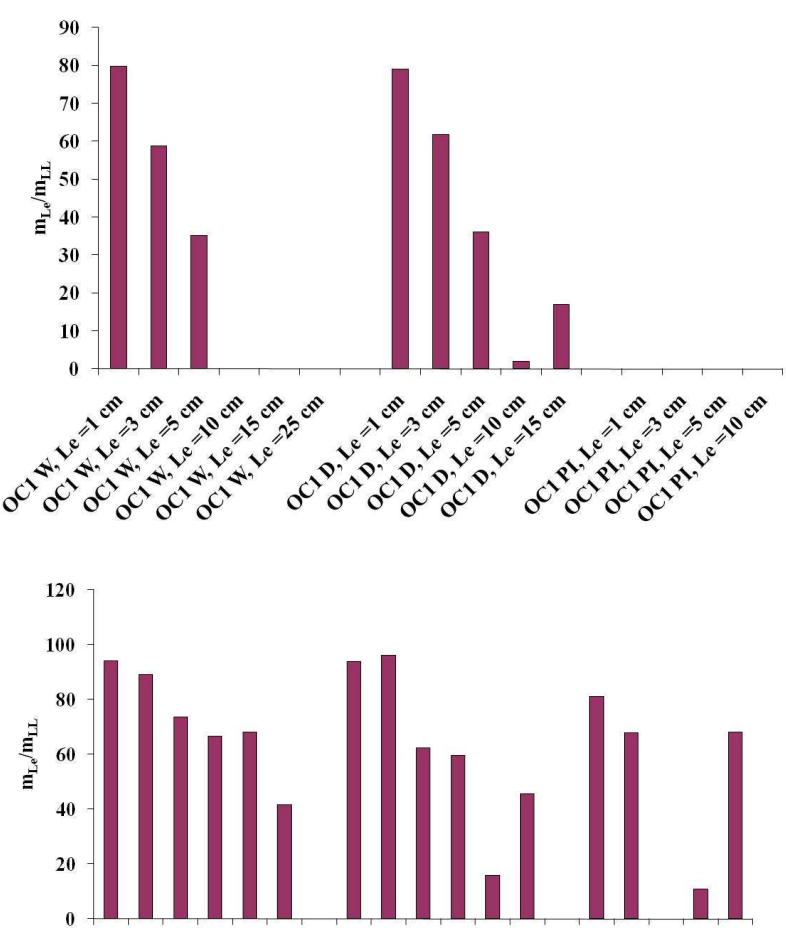

S
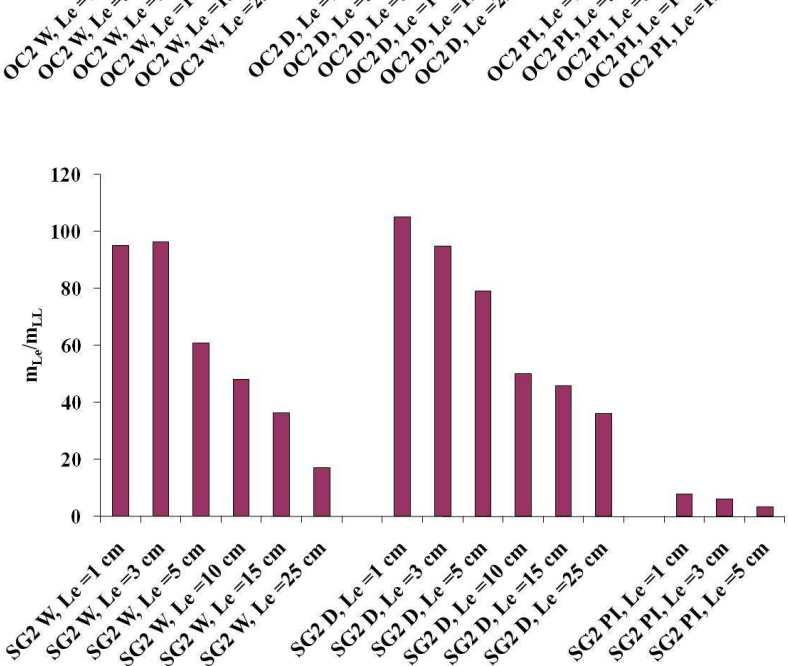

Figure 14. Values of $\mathrm{m}_{\mathrm{Le}} / \mathrm{m}_{\mathrm{LL}}$ vs. embedded length.

yarns, which explains why in some case the ratio exceeds $100 \%$ ).

Figure 14 gives the values of the ratio $\mathrm{m}_{\mathrm{Le}} / \mathrm{m}_{\mathrm{LL}}$ for the different yarns, pre-treatments and embedded lengths. The main trends that should be noted are the decrease of the ratio when the embedded length increases (for $\mathrm{OC} 1$, the ratio falls to zero when the embedded length is high enough), the similarity of $\mathrm{W}$ and D pre-treated yarns (except for OC2, PI pretreatment leads to much better anchoring of the filaments, which appears as a marked reduction of the $\mathrm{m}_{\mathrm{Le}} / \mathrm{m}_{\mathrm{LL}}$ ratio) and the specificity of OC2 yarn, which kept a large amount of core filaments, even for high embedded length.

\section{RELATIONSHIP TO THE IMPREGNATION}

\subsection{Optimal embedded length and efficiency}

Figure 15 gives the relationship between the optimal embedded length $\mathrm{L}_{\min }$, the efficiency and the impregnation index $\mathrm{I}_{\mathrm{y}}$ determined from SEM observation (see table 2 ).

The optimal embedded length is a decreasing function of the impregnation index. This is directly connected to the increase of cement paste presence inside the yarn, which reduces the distance between the anchorage points of the filaments.

The efficiency tends to increase when the impregnation index increases, which is linked to the increase of the sleeve filaments due to the penetration of the matrix in the yarn. It should be noted that the efficiency never reach $100 \%$.

OC1 and OC2 data are very similar, despite of the difference of structure of these two yarns. This may be related to the type of sizing, not design in this case for a use with concrete. Sizing for SG2 yarn is dedicated to concrete applications and favours the load transfer between yarn and matrix.

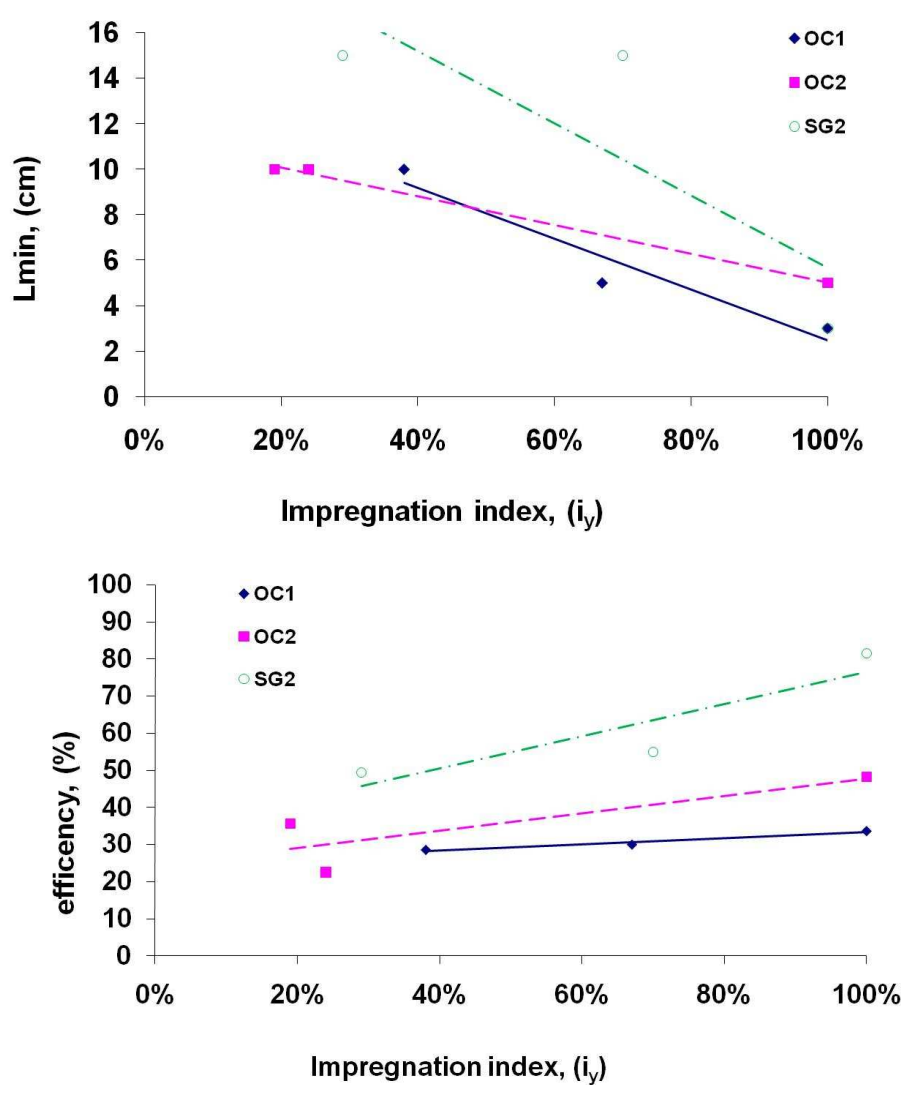

Figure 15. $\mathrm{L}_{\min }$ and $\mathrm{e}_{\mathrm{po}}$ vs. impregnation index $\mathrm{i}_{\mathrm{y}}$ 

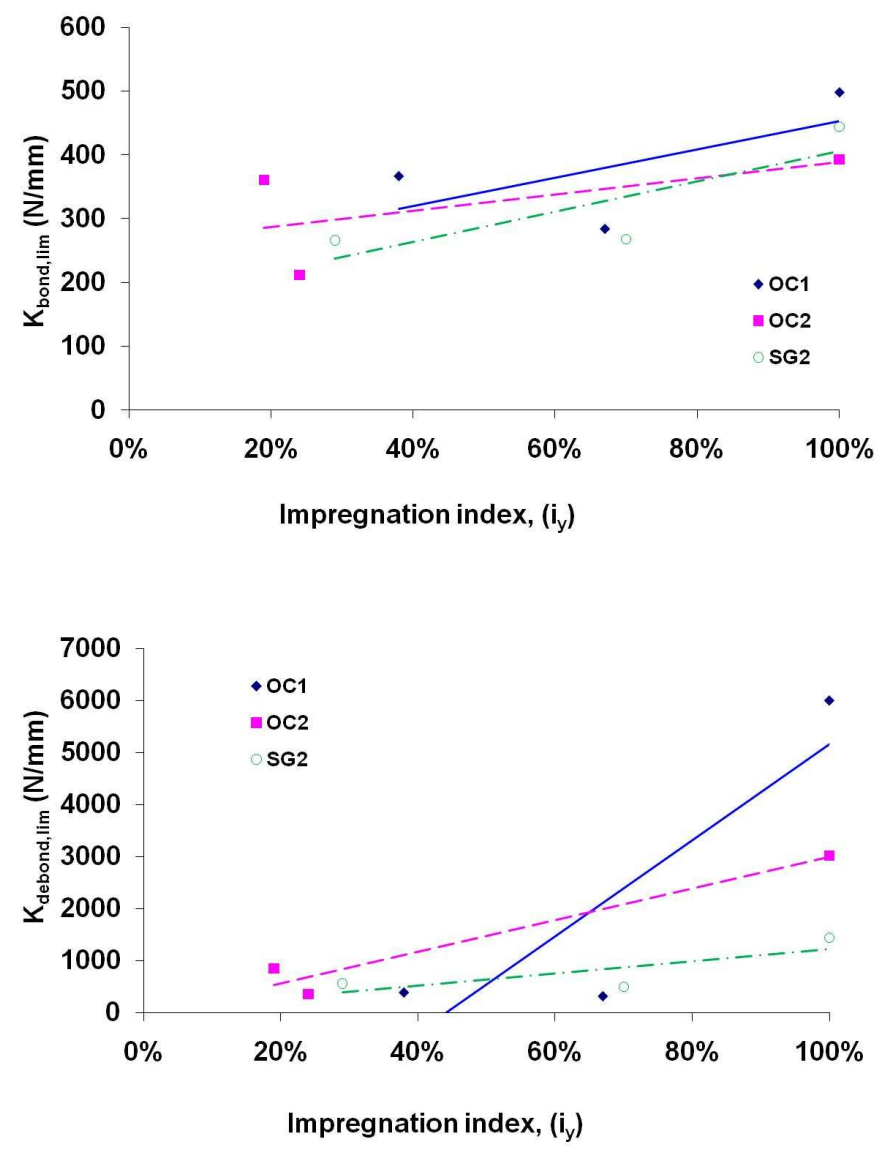

Figure 16. $\kappa_{\text {bond } \lim }$ and $\kappa_{\text {debond } \lim }$ vs. impregnation index $\mathrm{i}_{\mathrm{y}}$

Concerning the effect of the impregnation index on the stiffness, the three yarns, despite of their differences, roughly present the same increasing of $\kappa_{\text {bond } \lim }$ with the impregnation index (figure 16). This is consistent with the evolution of $\mathrm{L}_{\min }$ : when $\mathrm{L}_{\min }$ becomes lower, the working length of the filaments (i.e. length from the grip to the first anchorage point in concrete) decreases. As a consequence, the displacement is reduced for a given load, which traduces an increase of stiffness. Values of $\kappa_{\text {debond lim }}$ also increase with the impregnation index. They are about ten times highest than $\kappa_{\text {bond lim }}$ one for full impregnation. $\kappa_{\text {bond lim }}$ and $\kappa_{\text {debond lim }}$ are the values of $\kappa_{\text {bond }}$ and $\kappa_{\text {debond }}$ that correspond to $\mathrm{L}_{\min }$.

\section{CONCLUSION}

The results presented in this paper give detailed information on the influence of the pull-out behaviour of multi-filaments yarns. They show all the complexity induced by the non-monolithic structure of the yarn. This complexity is also a consequence of the variability generated by the specific constitution of yarns.

However, despite of this complexity, the experimental approach presented above allow the main parameters that determined the pull-out behaviour of the yarn to be highlighted. These parameters are the following: the structure of the yarn itself, its sizing, the embedded length, the state of the yarn before the casting of concrete. Most of these parameters influence the way the concrete penetrate the yarn at the time of casting and the resulting impregnation appears as playing a major part in the control of the pull-out behaviour. Impregnation, by influencing the partition between sleeve and core filaments, influences the maximum pull-out load and the efficiency of the yarn. It also determined the anchorage length necessary to reach the maximum efficiency of the yarn.

What is now needed is to take into account this complexity in models, so as to evaluate the effect of the different scenarios that can explain the pull-out behaviour.

\section{REFERENCES}

Aljewifi, H., Fiorio, B., Gallias, J.L. 2010. Caracterization of the impregnation by a cementitious matrix of five glass multi-filaments yarns. European Journal of Environmental and Civil Engineering, EJECE (in press).

Aljewifi, H., Fiorio, B., Gallias, J.L. Quantitative methods used to characterize the impregnation of a glass multifilament yarn by a cementitious matrix. $4^{\text {th }}$ Colloquium on Textile Reinforced Structures (CTRS4).3-5 June 2009. Dresden: Germany.

Chudoba, R., Vor`echovsky’, M., Konrad, M., 2006. Stochas tic modeling of multi-filament yarns. I. Random properties within the cross-section and size effect. International Journal of Solids and Structures 43: 413-434.

Hanisch, V., Kolkmann, A., Roye, A., Gries, T., 2006. Yarn and textile structures for concrete reinforcements. FERRO8, Bangkok, Febuary $6^{\text {th }}$.

Hegger, J., Bruckermann, O., Chudoba R., 2004. A smeared bond-slip relation for multi-filament yarns embedded in fine concrete. 6th International RILEM Symposium on Fibre Reinforced Concretes.

Kabele, P. , Novák, L., Nemecek, J., Kopecký, L., 2006. effects of chimical exposure on bond between synthetic fiber and cementitious matrix. ICTRC - 1st International RILEM Conference on Textile Reinforced Concrete 10: 91-99.

Langlois V. 2004. Etude du comportement mécanique des matériaux cimentaires à renforts synthétiques longs ou continues, PhD, Université de Cergy-Pontoise, France.

Naaman, A.E., Namure, G.G, Alwan, J.M., and Najm, H.S. 1991. Fiber pullout and bond slip. I: Analytical study. ASCE, Journal of Structural Engineering. 1117(9): 27692790.

Naaman, A.E., Namure, G.G, Alwan, J.M., and Najm, H.S. 1991. Fiber pullout and bond slip. II: Experimental validation. ASCE, Journal of Structural Engineering. 1117(9): 2791-2800.

Ohno S., Hannant, D.J., 1994. Modelling the stress-strain response of continuous fiber reinforced cement composites. ACI Materials Journal, vol. 91, 1994, p. 306-312. 